\title{
Pain in fibromyalgia and related conditions
}

\author{
G. Cassisi ${ }^{1}$, P. Sarzi-Puttini², R. Casale ${ }^{3}$, M. Cazzola ${ }^{4}$, L. Boccassini², \\ F. Atzeni ${ }^{2}$, S. Stisi ${ }^{5}$ \\ ${ }^{1}$ Rheumatology Branch, Specialist Outpatients Department, Belluno; \\ ${ }^{2}$ Rheumatology Unit, L. Sacco University Hospital, Milano; \\ ${ }^{3}$ Department of Clinical Neurophysiology and Pain Rehabilitation Unit, Foundation Salvatore Maugeri, \\ IRCCS, Scientific Institute of Montescano, Montescano (PV); \\ ${ }^{4}$ UOC Medicina Riabilitativa A.O. "Ospedale di Circolo", Saronno (VA); \\ ${ }^{5}$ A.O. r.n. "G. Rummo" Benevento, Italy
}

\section{SUMMARY}

Pain is the hallmark symptom of fibromyalgia (FM) and other related syndromes, but quite different from that of other rheumatic diseases, which depends on the degree of damage or inflammation in peripheral tissues. Sufferers are often defined as patients with chronic pain without an underlying mechanistic cause, and these syndromes and their symptoms are most appropriately described as "central pain", "neuropathic pain", "nonnociceptive pain" or "central sensitivity syndromes". The pain is particular, regional or widespread, and mainly relates to the musculoskeletal system; hyperalgesia or allodynia are typical. Its origin is currently considered to be distorted pain or sensory processing, rather than a local or regional abnormality.

FM is probably the most important and extensively described central pain syndrome, but the characteristics and features of FM-related pain are similar in other disorders of particular interest for rheumatologists, such as myofascial pain syndromes and temporo-mandibular joint disorders, and there is also an intriguing overlap between FM and benign joint hypermobility syndrome. This suggests that the distinctive aspects of pain in these idiopathic or functional conditions is caused by central nervous system hypersensitivity and abnormalities. Pharmacological and non-pharmacological therapies have been suggested for the treatment of these conditions, but a multidisciplinary approach is required in order to reduce the abnormal cycle of pain amplification and the related maladaptive and self-limiting behaviours.

Key words: Fibromyalgia, Pain, Central pain syndromes, Myofascial pain syndromes, Temporo-mandibular disorders, Benign joint hypermobility syndrome.

Reumatismo, 2014; 66 (1): 72-86

\section{INTRODUCTION}

Dair ain is the hallmark symptom of fibromyalgia (FM) and other related syndromes. The pain of FM is quite different from that of other rheumatic diseases and, unlike arthritis, osteoarthritis or other painful soft tissue conditions, cannot be adequately explained on the basis of the degree of peripheral tissue inflammation or damage. Sufferers are often defined as patients with chronic pain without an underlying mechanistic cause, and those syndromes and symptoms form part of a much larger continuum whose many names include functional somatic syndromes, medically unexplained symptoms, chronic multi-symptom illness, and somatoform disorders (1), as well as more appropriate contemporary terms such as "central pain", "neuropathic pain", and "non-nociceptive pain" (2). However, probably the best nosological term for these complaints is that of "central sensitivity syndromes" (CSS) proposed by Yunus $(3,4)$.

Other rheumatic diseases do not have pain as their dominant symptom, most important feature or main patient complaint, and their diagnostic and classification criteria do not often include pain as a specific domain, but the conditions mentioned above would not exist without the particular and usually unremitting regional or widespread pain that mainly affects the musculoskeletal system. Patients typically suffer from hyperalgesia (increased pain induced by normally painful stimuli) 
or allodynia (pain induced by normally non-painful stimuli), thus suggesting that the original problem is distorted pain or sensory processing rather than a local or regional abnormality.

FM is probably the most important and widely described of the central pain syndromes, but other idiopathic or functional disorders also suggest that the pain does not come from the periphery but is due to an underlying aberrant mechanism of the central nervous system (CNS) that causes hypersensitivity and accounts for the distinctive aspects of the related pain.

\section{The concept of central sensitisation or sensitivity}

Central sensitisation (CS) can be defined as an incorrect and abnormal response of the CNS to a peripheral stimulus, due to neuronal hyperexcitability and hypersensitivity, and characterised by prolonged or persistent pain. CS has many neurophysiological aspects, including enhanced spinal cord dorsal horn neuronal excitability and increased spontaneous neuronal activity, an enlarged receptive field (the "windup" phenomenon), and increased stimuli transmitted by large- and small-diameter primary afferent fibers (5). These inappropriately anomalous events lead to an exaggerated painful perception of normal non-painful stimuli, such as touch or gentle pressure (i.e. allodynia).

Persisting stimuli from the periphery (due to the activation of a variety of nociceptors in the presence of inflammatory mediators such as bradykinin, serotonin, histamine, prostaglandins, and substance P), peripheral sensitisation, converging phenomena at wide dynamic range neuron level in the dorsal horn, and the wind-up phenomenon cause what is known as "neuroplasticity". The wind-up phenomenon, which progressively increases the response of secondary neurons (following repeated stimulation of $\mathrm{C}$ fibres), is mediated by $\mathrm{N}$-methyl-Daspartate (NMDA), and NMDA receptors seem to be strictly related to the escalating hyperexcitability of second-order neurons. It is not clear whether these phenomena are due to spinal sensitisation maintained by the input of tonic impulses from somatic tissues, a facilitating mechanism within the brain, or an abnormal mechanism of descending facilitation (6). Neurotransmitter abnormalities also play a role in pain and sensory processing by increasing "volume control" $(1,7)$, but long-term neuroplasticity itself can lead to self-sustaining CS without the need for further stimuli (8).

FM and other functional somatic syndromes characterised by disturbed central pain processing are not characterised by a demonstrable inflammation or mechanical tissue damage, injury, or entrapped peripheral nerves, but there is no doubt that they have some neuropathic aspects and that any combination of peripheral, neuropathic and central pain may be present in a given individual (1).

Finally, neurotransmitters, cytokines or chemokines can also activate glial cells, and thus contribute to secondary enhancement of the CNS and CS $(5,9)$.

CS therefore seems to be the pivotal component of the central pain mechanism and process of amplification that lead to the clinical manifestation of sensitivity (4).

\section{FIBROMYALGIA}

\section{Pain definitions and classification and diagnostic criteria}

The most common and distinctive symptom of FM, one of large group of soft tissue pain syndromes, is pain and FM is currently classified as a chronic widespread pain (CWP) characterised by extensive hyperalgesia and allodynia (10).

The 1990 American College of Rheumatology (ACR) definition for clinical trials stated that FM is a CWP condition with characteristic tender points upon physical examination, often associated with a constellation of symptoms such as fatigue, sleep disturbances, headache, irritable bowel syndrome, and mood disorders (11). Widespread pain for at least three months and tenderness at definite points were the two compulsory major criteria for classifying adult FM. This definition 
is still broadly accepted, although further elucidations and revisions have been proposed.

Pain is usually associated with fatigue and sleep disturbances in virtually all patients with FM, and these are considered the three key features of the syndrome (12).

The 1992 Copenhagen declaration emphasised that FM is the commonest cause of chronic widespread musculoskeletal pain in a non-articular condition, predominantly involving muscles (13).

CWP for at least three months is the requisite unifying every attempt to draw up classification or diagnostic criteria during the time $(11,14,15)$.

The new ACR preliminary diagnostic criteria for FM suggest the use of the Widespread Pain Index as a method of identifying and enumerating the painful areas reported by patients, although many other somatic symptoms are considered crucial with the view that FM is a CSS. They also introduced an innovative and debatable concept of widespread pain that encompasses the possibility that it can be considered diffuse even if it is regional.

\section{Characteristics of pain}

Pain is usually present in all four limbs, as well as the upper or lower back; many patients state that they "hurt all over", and this symptom is often a discriminant when evaluating patient complaints. It may be regional or generalised and "nonanatomically" distributed, and perceived as originating in muscles or deep in bones (16), and rarely articular (17); no structural or nerve root distribution can be detected. Hyperalgesia and allodynia, persistent pain, summation effects, skin hyperpathia, and tenderness upon examination are the most common characteristics, and patients describe their pain as sharp, burning, searing, tingling, shooting or stabbing, deeply aching, or feeling bruised all over $(10,16)$. Its intensity is aggravated by cold or humid weather, anxiety or stress, overuse or inactivity, poor sleep $(18,19)$ and noise $(20)$. The pain often corresponds to widespread, regional or localised myalgia, not necessarily confined to the tender points, and with widely varying characteristics. Leg cramps are reported in approximately $40 \%$ of FM patients as against $2 \%$ of controls (21).

In a very recent and extensive study, FM pain reached the utmost level of intensity among rheumatic diseases, with a mean value of 71.7 measured on a Visual Analogue Scale (22).

Finally, tenderness is the unique and typical sign, but is not limited to the canonic tender points (23)

\section{Pain mechanisms}

The pathophysiology of FM is still unclear, although many of its aspects have been clarified over the last few decades. The different research areas are now well defined: genetics, triggers, psychophysiological abnormalities, autonomic nervous system dysfunction, neurotransmitter and neuroendocrine dysfunctions, and cerebral abnormalities, but CNS hypersensitivity is the most relevant event and CS appears to be its main mechanism. Emerging evidence suggests that people experiencing regional pain may develop widespread pain: for example, some authors have found that $10-22 \%$ of subjects with chronic neck pain or whiplash injuries develop CWP or FM $(24,25)$.

FM patients also present neurotransmitter abnormalities at different levels and various neuropeptides can induce the expression of cytokines at nerve endings, thus increasing nociceptive sensitivity $(6,26$, 27). In addition, decreased thresholds of heat (28), auditory tones (29) and electrical stimulation $(30,31)$ have been demonstrated, which suggests that FM (like its related syndromes) may involve the biological amplification of all sensory stimuli (32).

Can the neurochemical model completely and entirely explain CS? Or are psychological and sociological aspects (partially or totally) additional factors promoting the change in pain perception? Familial predisposition, genetic polymorphism, and differences between male and female patients must be taken into account (33-35).

Neuroimaging of brain activity has allowed us to understand some of the cer- 
ebral mechanisms and abnormalities involved in CS. Some authors have found increased activity in the brain's pain processing regions (the rostral anterior cingulate cortex and pre-frontalcortical areas) during painful mechanical stimulation $(36,37)$, and the insula seems to be the most reliably hyperactive region (1). Increased sensitivity in FM has been demonstrated by a controlled study of the effects of an evoked painful stimulus: equivalent pressure stimuli induced significantly greater activity in the patients, whereas similar levels of perceived pain intensity evoked similar neural activity in a network of brain regions involved in pain processing in patients and controls $(32,38)$. It is not always easy to show whether functional magnetic resonance (fMR) findings in FM are only due to hyperalgesia or reflect cognitive effects. Experimental evidence strongly supports the view that FM symptoms are related to dysfunctions in the CNS associated with multiple changes in the brain, but whether long-term ongoing pain causes the changes, or the changes cause the pain, is still an open question (39).

Neuroendocrine abnormalities play an important role in the pathogenesis of FM. The hypothalamic-pituitary-adrenal and hypothalamic-pituitary-thyroid axes show functional alterations, and it is known that chronic stress can induce the functional exhaustion of stress responses and contribute to increased pain perception. FM patients have an abnormal response to stress and an inadequate reaction to a number of stressful events (7). Chronic stress and persistent pain can also modulate emotional responses. The amygdala seems to play a dual facilitatory and inhibitory role in modulating pain behaviour and nociceptive processing at different levels of the pain neuraxis. Negative or positive emotions may respectively amplify or reduce the pain perception as a result of amygdala plasticity (40).

Other conditions may influence or alter the perception of pain. Relationships between sleep disturbances and pain in FM have been noted since the first study dem- onstrating that sleep deprivation induces FM-like tenderness (41), and various researchers have suggested a bidirectional relationship between non-restorative sleep and pain in FM (42). The association between FM and depression and anxiety has been confirmed $(43,44)$ and both depression and anxiety (often manifest in FM patients) can affect the ability to cope with everyday life events. Moreover, emotional and cognitive processes, which depend on individual vulnerability and strength, may affect responses (6). A close correlation between depression/anxiety and FM activity has recently been demonstrated using the FM Assessment Status Index (45). Lastly, some fMR findings are highly important. In the presence of FM-related major depressive disorder, significant activity has been detected in the brain regions traditionally related to the affective component of pain, which suggests that pain can be modulated by depression (46). The experience of pain is multidimensional and subjective, and it has been demonstrated that patients who believe in their personal ability to control their pain fare better than those who believe that it is due to external factors or influences. The former (who belong to the so-called "internal locus of control") show greater activation in the areas involving the evaluation of pain than the latter, who belong to the "external locus of control" and show a greater response in the areas involving sensory integration $(38,47)$.

Finally, catastrophising behaviour has a significant influence on pain perception and is strictly related to the brain regions that mediate attention, anticipation or emotional response to pain (37).

\section{RELATED CONDITIONS}

Pain is the key symptom in some FM-related conditions or associated syndromes. The construct of CSS elegantly and fairly explains the concept of an overlapping or similar group of syndromes without a structural pathology that are characterised by the common mechanism of CS. These 
Table I - Central sensitivity syndrome.

\begin{tabular}{|l|}
\hline Fibromyalgia \\
\hline Chronic fatigue syndrome \\
\hline Irritable bowel syndrome \\
\hline Tension-type headache \\
\hline Migraine \\
\hline Temporo-mandibular disorders \\
\hline Myofascial pain syndrome \\
\hline Restless legs syndrome \\
\hline Periodic limb movements in sleep \\
\hline Multiple chemical syndrome \\
\hline Primary dysmenorrhea \\
\hline Female urethral syndrome and interstitial cystitis \\
\hline Post-traumatic stress syndrome \\
\hline
\end{tabular}

share a number of features and biopathophysiological mechanisms, and have become better defined over time. In addition to FM, the latest redefinition of the CSS family includes twelve functional disorder (Tab. I). Depression and Gulf war syndrome have been postulated as potential new members $(3,8)$.

A number of these conditions present musculoskeletal pain, usually in the form of chronic local, regional or widespread pain. Myofascial pain syndrome (MPS) and temporo-mandibular joint disorders (TMJDs) are musculoskeletal conditions of particular interest for rheumatologists. Benign joint hypermobility syndrome (JHS), which does not belong to the CSS family and is generally considered the least severe and most frequent type of Ehlers-Danlos syndrome (EDS), has similar features and an intriguing overlap with FM.

\section{Myofascial pain syndromes}

Pain definitions and diagnostic criteria MPS is frequent condition in the general population and one of the most common causes of pain and dysfunction among musculoskeletal symptoms. Myofascial trigger point pain syndrome is the name that best describes the specific clinical manifestation of muscle pain arising from trigger points. Its general population prevalence is unknown, but its prevalence among patients complaining of pain any- where in the body ranges from $30 \%$ to $93 \%(48,49)$. The pain typically originates from a myofascial trigger point (TP) that usually causes a localised and referred response associated with a complex of sensory, motor and autonomic symptoms. Mandatory criteria for a diagnosis of MPS are a patient report of pain and finding the TP in a taut palpable band. The pain is localised at a specific point along the band and in an expected referred area for a given TP. Exquisite and localised tenderness and the reproduction of spontaneously perceived pain by TP pressure are two of the re-defined 1999 Simons criteria (50) (Tab. II). A survey of expert American clinicians pointed out that a regional distribution of the symptoms and signs, the presence of TP, and a normal neurological examination are the minimal criteria for the diagnosis of MPS (51), however, there are no universally accepted clinical criteria for a diagnosis of MPS.

\section{Characteristics of pain}

MPS patients usually present deep, tensive and constrictive somatic pain that is occasionally cramp-like and may have a sudden or gradual onset. It varies in intensity, may be continuous or intermittent,

Table II - Myofascial pain syndrome - Simons' redefined 1999 diagnostic criteria.

\begin{tabular}{|l|}
\hline Major criteria \\
\hline Localized spontaneous pain \\
\hline $\begin{array}{l}\text { Spontaneous pain or altered sensations in the } \\
\text { expected referred area for a given TP (target area) }\end{array}$ \\
\hline A taut, palpable band in an accessible muscle \\
\hline $\begin{array}{l}\text { Exquisite, localized tenderness in a precise point } \\
\text { along the taut band }\end{array}$ \\
\hline $\begin{array}{l}\text { A certain degree of reduced range of movement when } \\
\text { measurable }\end{array}$ \\
\hline Minor criteria \\
\hline $\begin{array}{l}\text { Reproduction of spontaneously perceived pain and } \\
\text { altered sensations by pressure on the TP }\end{array}$ \\
\hline $\begin{array}{l}\text { Elicitation of an local twitch response of muscle fibers } \\
\text { by transverse 'snapping' palpation or by needle } \\
\text { insertion into the TP }\end{array}$ \\
\hline $\begin{array}{l}\text { Pain relieved by muscle stretching or injection of the } \\
\text { TP }\end{array}$ \\
\hline $\begin{array}{l}\text { Diagnosis: major criteria + one out of three minor } \\
\text { criteria. }\end{array}$ \\
\hline
\end{tabular}

TP, trigger points. 
and is generally present at rest (less frequently during movement). Clearly distinguishable, pain is spontaneous, and the related TP is defined "active". Tenderness upon localised compression is another important characteristic that may also appear if the TP is silent (i.e. in the absence of spontaneous pain); in this case, the TP is defined "latent" and should be properly identified in order to prevent possible evolution (50). TP palpation or therapeutic injection may elicit a local twitch response of muscle fibres (some authors consider this fleeting response one of the hallmarks of MPS).

MPS pain may be localised to the area of the affected muscle or at a distance from it, and its pattern is typical for each muscle. Patients do not usually complain of articular discomfort, although some referred areas correspond to a joint. MPS frequently affects the muscles working against gravity, particularly the neck and low back, head, shoulders and hips. Weakness, stiffness, fatigue and poor working tolerance are frequent, and autonomic dysfunction may be present depending on the muscle site $(52,53)$.

Finally, the differences between MPS and FM pain must be considered because about $70 \%$ of FM patients also have a local or regional MPS $(54,55)$. MPS and FM may overlap, but multi-regional MPS may be mistakenly diagnosed as FM and physicians must therefore recognise the characteristics of the pain listening to patient's complaints.

\section{Pain mechanism}

MPS is strictly regional, and the pain and sensory changes are confined to the affected area. The pain threshold is low at TP level $(56,57)$. In painful areas, the lowered pain threshold not only involves the muscle, but also the overlying subcutis and skin whereas, in non-painful areas, the threshold is normal (52).

The crucial element for the development of a TP is probably dysfunctional neuromuscular endplate activity. Spontaneous endplate activity has been demonstrated at the so-called "active loci" (i.e. the motor endplates). Sensitised nociceptors that account for local and referred pain are "sensitive loci".

Multiple "sensitive" and "active" loci represent a TP region in which the spontaneous release of acetylcholine (Ach) seems to be responsible for endplate hyperactivity $(52,56,58)$, and needle and surface electromyography seems to corroborate this $(56,59)$. Increased Ach concentrations in the synaptic cleft, changes in the activity of a number of Ach receptors, and changes in Ach esterase activity may explain the increased endplate electrical activity of the active TP.

Pain occurs because of the local release of substances from damaged muscle, or during the course of ischemia or exercise; these substances activate muscle nociceptors that increase motor endplate activity (58). Unaccustomed eccentric exercise that stresses a muscle beyond its tolerance is probably the main cause of the TP. The consequent hypoperfusion leads to an acidic milieu and hypoxia that provoke increased Ach activity and miniature endplate potentials, and a substantial increase in the release of calcitonin gene-related peptide. The terminal consequences of the cascade are sarcomere hypercontraction due to the continuous release and inadequate re-uptake of calcium ions, and taut band formation. If these persist, hypoxia and nociceptive substances cause a negative, self-maintaining cycle leading to chronic hypersensitivity to pain $(56,58,60)$.

It is widely accepted that MPS becomes a chronic form of pain and other complaints unless promptly well treated. In the case of chronicity, the continuous barrage of nociceptive input from an active TP may induce CS and the consequent spreading of the pain to other regions. Active TPs may be inactivated by therapy, but usually recur in the presence of triggering conditions, and this may play a role in the onset of FM in subjects with predisposing factors. Furthermore, tenderness and referred pain related to chronic musculoskeletal pain may be due to peripheral and central sensitisation, both of which are probably essential events in the transition from 
acute to chronic pain. Moreover, persistent painful inputs from a TP may increase the degree of CS at different levels of the CNS; consequently, the transmission of pain messages due to other conditions is facilitated $(52,61)$.

Finally, the mechanisms underlying two characteristics of TPs are not clearly understood: secondary TP (a nociceptive focus in a different muscle when the primary TP is active) and referred pain from the primary TP probably represent a combination of local sensitivity and CS. A secondary TP could be due to the neurogenic expression of CS; neurogenically mediated inflammation causes the release of inflammatory mediators and neuropeptides, thus leading to sensitisation of peripheral nociceptors and, subsequently, TP formation $(62,63)$. Referred pain from

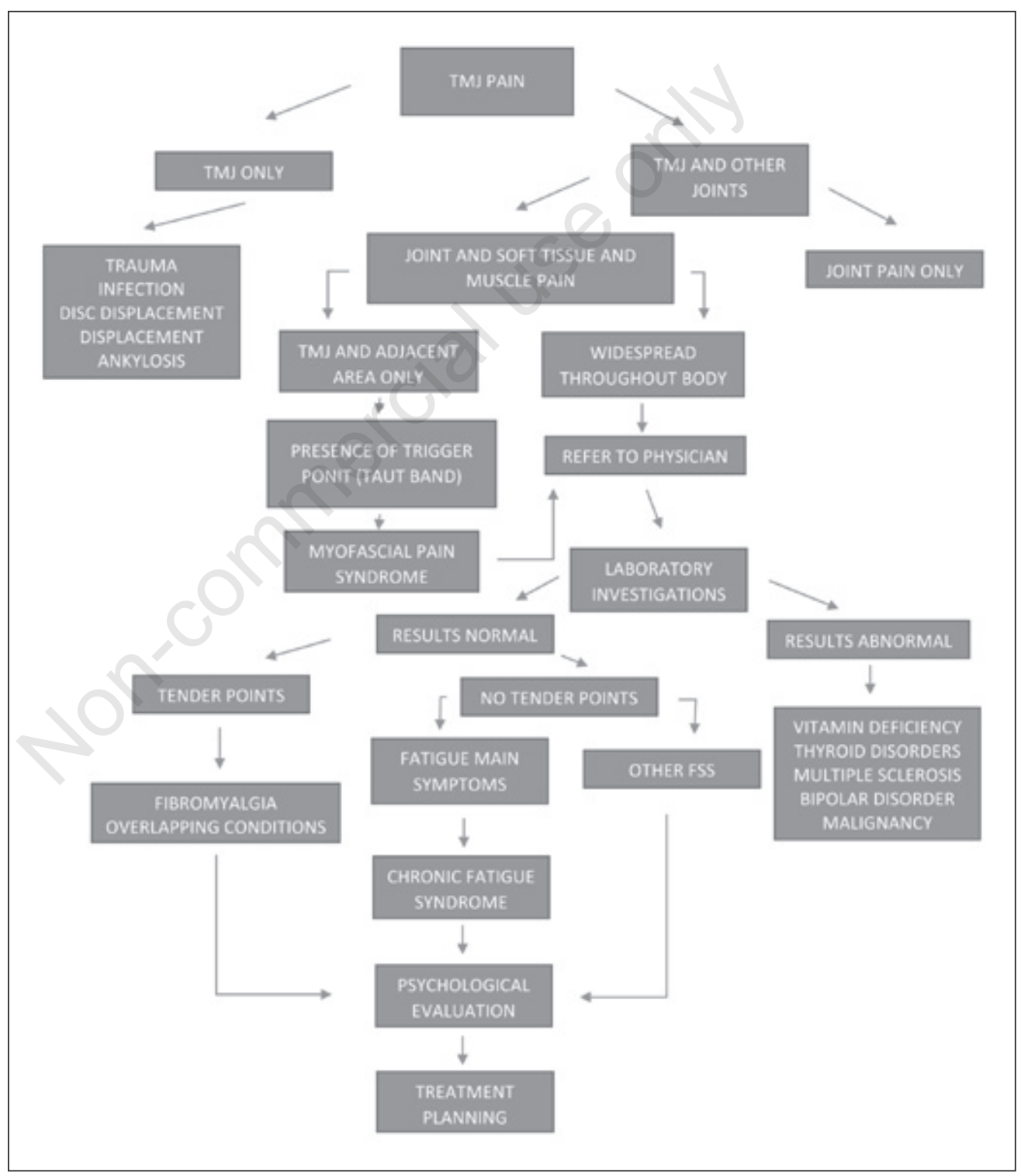

Figure 1 - Clues to diagnosis of functional somatic syndromes presenting with temporomandubular disorders (modified from Suma S, Veerendra Kumar B. Temporomandibular disorders and functional somatic syndromes: deliberations for the dentist. Indian J Dent Res. 2012; 23: 529-36). 
a TP may be attributable to central hyperexcitability phenomena such as convergence and facilitation, in the same way as referred pain arises from the viscera (64), because of the spread of CS to adjacent spinal segments (65).

\section{Temporo-mandibular joint disorders}

TMJDs are a comprehensive term that embraces a number of clinical problems involving the masticatory muscles, the temporo-mandibular joint and associated structures; it belongs to the CSSs and shares many of non-painful symptoms.

The most important feature is pain, followed by restricted mandibular movement and noises from the joints during jaw movement. It has a negative impact on the quality of life and increases stress levels $(66,67)$ in a manner that is strictly related to difficulties in management and, therefore, chronicity. TMJDs are very common: it affects about $20-30 \%$ of the adult population to some degree (68), and $60-70 \%$ of the general population have at least one sign of the disorder (69). It usually appears in people aged 20-40 years, and is more common in females; TMJDs are the second most frequent cause of orofacial paon after that of dental origin (70). Trauma, inflammation, aging, parafunctional habits, infections, and neoplasms must all be considered in the differential diagnosis before considering TMJD a CSS or functional somatic syndrome (as other authors prefer) (71) (Fig. 1).

Pain definitions and classification criteria TMJDs are a cluster of related disorders with many common features that has widely varying definitions and terminology, although the term "temporo-mandibular joint disorder" is generally favoured. There are no universally accepted classification or diagnostic criteria.

The Research Diagnostic Criteria $(72,73)$ consider temporo-mandibular disorders (TMD) in 2 axes; axis I refers to physical aspects, and axis II involves the assessment of psychological status, mandibular function and TMD-related psychosocial disability (74). Axis I is further divided into three general groups: group I are muscle disorders; group II are disc displacements; and group III are joint disorders (72). Pain is the main symptom of all these groups, although limited range and noises from the joint during mandibular movement are cardinal symptoms and signs in TMJDs. It may be acute or chronic (when the symptoms last for more than three months), and may be often and indiscriminately referred to muscle or joint structures. TMJD-related pain has been variously classified as "facial arthromyalgia", "myofacial pain dysfunction syndrome", "craniomandibular dysfunction", "myofacial pain dysfunction", "masticatory myalgia", "mandibular dysfunction", or headache or facial pain by different scientific societies, academies or organisations.

\section{Characteristics of pain}

The cardinal features are included in the definitions of the disorder. Tenderness upon palpation of the masticatory muscles or of the joint itself (usually just in front of the ear) is another characteristic of TMJDs pain. Manipulation or function (chewing, clenching or yawning) usually increases the level of pain (75), which is often worse upon waking than during the night or rest (76). The pain is usually described as dull or aching, poorly localised, intermittent or (sometimes) constant, but rarely severe $(77,78)$. It is more usually unilateral than bilateral (79), and may occur not only in the joint region, but can also be referred to the temple, neck and shoulders.

\section{Pain mechanism}

Like other CSS, TMJD has a multifactorial etiology, and the presence of predisposing, initiating, precipitating and perpetuating factors need to be recognised (except when it is due to structural causes) (80) for the construct of the bio-psychosocial model that bonds all of the members of the CSS family. As in FM, MPS and other related syndromes, CS is the most plausible underlying mechanism that progressively makes the pain chronic and locally widespread.

The pain discourages the use of the mas- 
ticatory system as a "fear avoidance" behaviour, which leads to reduced muscle elasticity, tone, strength, endurance and, eventually, incomplete mouth opening (81). Anxiety, depression, somatisation, and sleep deprivation are important risk factors for the development of TMJDs, and may amplify the syndrome itself (82). Finally, it has also been reported that TMJDs are associated with other conditions such as FM, MPS, chronic fatigue syndrome, tension-type headache, and interstitial cystitis (83). It has been demonstrated that $75 \%$ of TMJDs patients could also be diagnosed as having FM and, conversely, that $18 \%$ of FM patients meet the diagnostic criteria for TMJDs (84). These chronic pain conditions probably share similar pathophysiological mechanisms. Although TMJDs are a localised disorder and FM is characterised by widespread pain, peripheral sensitisation and CS may be the link between them.

\section{Benign joint hypermobility syndrome}

JHS is the most frequent type of EDS (about 90\%), a group of hereditary connective tissue diseases characterised by joint hyperlaxity, mild skin hyperextensibility, tissue fragility and extra-musculoskeletal manifestations (85) (Tab. III). JHS and other types of EDS are genetically determined, and correspond to structural damage typically localised in discrete anatomical sites; they therefore cannot be considered as belonging to the CSS family. Nevertheless, some typical features and scientific reports of the frequent association of JHS with some CSS (particularly FM) suggests that there may be some pathophysiological correlations.

Pain is not one of the major diagnostic

Table III - Types of Ehlers-Danlos syndrome.

\begin{tabular}{|l|}
\hline Classic (Type I and II) \\
\hline Hypermobile type (Type III) \\
\hline Vascular type (Type IV) \\
\hline Kyphoscoliosis type (Type VI) \\
\hline Arthrochalasia type (Types VII A and B) \\
\hline Dermatosparaxis type (Type VII C) \\
\hline Other types \\
\hline
\end{tabular}

criteria of JHS; chronic joint, limb, and/ or back pain are only minor criteria that support but are not sufficient to establish a diagnosis (85). However, musculoskeletal pain is a frequent patient complaint and, although its relationship with hypermobility (HM) has not yet been defined, HM was the primary cause of musculoskeletal pain in most of the $6 \%$ of affected children at a pediatric clinic (86), and an association between HM and soft tissue rheumatism has been reported (87). The laxity of the joints could predispose some JHS patients to develop musculoskeletal pain, joint and muscle stiffness, and sometimes widespread pain (88).

Some authors have studied the possible relationship between JHS and FM but reached different conclusions (89-91). A historical editorial underlined the increasing evidence that at least a sub-group of patients with soft tissue musculoskeletal pain, widespread pain, or FM were hypermobile, and highlighted the fact that HM might be considered a contributing mechanism to the development of widespread pain or FM in some individuals (92). More recently, Turkish authors have demonstrated that the frequency of joint HM was significantly higher in the FM groups than in the control groups of two different studies (respectively $64.2 \%$ vs $22 \%$, and 46.6 vs $28.8 \%)(93,94)$.

HM is associated with specific and significant mechanical stresses at the joint and entheses. Migratory non-deforming musculoskeletal pain is present in children and adults. As in the case of an overuse syndrome, some of these presentations may be due to repetitive or transient microtraumas (95).

Moreover, HM is also frequently associated with anxiety, panic attacks, and unexplained chest pain $(96,97)$, which are probably the expression of dysregulated autonomic function. HM might be considered as a marker of the potential development of autonomic dysregulation, especially in the setting of intense or prolonged sympathetic/fight-or-flight stimuli (95).

Impairment and the impact of pain have been recently studied in female patients 
with EDS HM type, the burden of which was compared with that of FM or rheumatoid arthritis. The EDS group reported similar physical and overall function, and better psychological function than the FM group, whereas their levels of pain severity, life interference, and affective distress were significantly lower (98).

In conclusion, JHS should be taken into account as a possible trigger of widespread pain or FM in susceptible subjects. Excessive or inappropriate physical activity, with the consequent hyperextension of the joint capsule and repeated micro-traumas of ligaments and muscles, could lead to the over-activation of pain receptors in the joints and, by causing hypersensitivity and amplifying pain signals, could generate more widespread pain or trigger the typical symptoms of FM.

\section{THERAPEUTIC APPROACHES}

Treating the pain associated with FM and related conditions is a great challenge. Pain is the most frequent complaint of patients, especially those with the diseases described in this paper; clinicians are well aware of the fact that every treatment must take into account the associated symptoms, which need to be graded and prioritised. Various drug and non-drug therapies have proven positive effects on at least some CSS and, more generally, chronic pain.

Over the last few decades, substantial advances have been made in the treatment of these disorders, particularly for the pharmacological options, on the basis of our greater understanding of the pathophysiology of FM, our improved knowledge of CS mechanisms, and our ability to define symptom domains more precisely. Experts have pointed that a multidisciplinary approach is essential (99-103) as physicians need to bear in mind all of the potential comorbidities and overlapping conditions in order to avoid treatment failures and ensure that the most active problem is confronted in a timely and effective manner.

Well-designed and controlled clinical trials have shown that various classes of neuromodulatory agents can be helpful. Drugs that act on the noradrenergic and serotonergic pain pathways, or the ascending nociceptive pathways, and those that can improve other symptom domains such as fatigue, disturbed sleep and cognition, are available.

The treatment of FM is the most complete and extensively analysed, and the drugs that work well and have a high level of evidence in FM are also useful in some patients with other CSS. There is strong evidence in favour of dual re-uptake inhibitors such as tricyclic compounds (amitriptyline, cyclobenzaprine) and serotonin-norepinephrine reuptake inhibitors (milnacipram, duloxetine, venlafaxine) and for anticonvulsants (pregabalin and gabapentin); moderate evidence for tramadol, selective serotonin reuptake inhibitors, gamma hydroxybutyrate and dopamine agonists; and weak evidence for growth hormone, 5-hydroxytriptamine, tropisetron, S-adenosyl-L-methionin. There is no evidence in favour of opioids, corticosteroids, non-steroidal anti-inflammatory drugs (NSAIDs), or the benzodiazepines, and some data suggest that giving opioids to patients with central pain states might even worsen the pain $(1,104,105)$.

The European League Against Rheumatism recommendations share this pharmacotherapeutic grading, but also strongly recommend tramadol and pramipexole and state the potential effectiveness of simple analgesics such as paracetamol and other weak opioids (99).

Ketamine, amitriptyline, and gabapentin are considered specifically effective in attenuating CS (8).

No pharmacological options have ever been beneficial in treating MPS, for which the deactivation of TP is the gold standard; muscle stretching and TP injections are by far the most effective means of relieving symptoms $(50,52)$. Analgesics and non-steroidal anti-inflammatory drugs can modulate the pain, but have no definite action on TP. Muscle relaxants are not useful (106).

Medication is the main method of managing the pain associated with TMJDs, 
and the pharmacological options are not substantially different from those of other CSSs, particularly FM. Although many randomised and controlled clinical trials have been conducted to test these widely used drugs, a recent systematic review has shown that there is a lack of evidence in favour or against their use (75).

The presence of a clearer peripheral origin of pain and consequent potential peripheral sensitisation probably supports the use of non-narcotic analgesics, NSAIDs, and weak and strong opioids in TMJD and JHS, reserving strong opioids to the subset of patients who obtain no benefit from other therapies $(107,108)$.

Non-pharmacological therapies vary widely and it is often difficult to draw any conclusions concerning their value. However, physical therapy, the correction of abnormal postural or perpetuating factors, and different complementary and alternative medicines have often been suggested in order to improve the response to medication in a multidisciplinary manner and reduce the abnormal cycle of pain amplification and its related maladaptive and self-limiting behaviours $(52,85,103,109$, 110).

\section{REFERENCES}

1. Phillips K, Clauw DJ. Central pain mechanisms in chronic pain states - maybe it is all in their head. Best Pract Res Clin Rheumatol. 2011 ; 25: 141-54.

2. Clauw DJ. Fibromyalgia: update on mechanisms and management. J Clin Rheumatol. 2007; 13: 102-9.

3. Yunus MB. Central sensitivity syndromes: a unified concept for fibromyalgia and other similar maladies. J Indian Rheum Assoc. 2000; 8: 27-33.

4. Yunus MB. Central sensitivity syndromes: a new paradigm and group nosology for fibromyalgia and overlapping conditions, and the related issue of disease versus illness. Semin Arthritis Rheum. 2008; 37: 339-52.

5. Staud R, Smitherman ML. Peripheral and central sensitization in fibromyalgia: pathogenetic role. Curr Pain Headache Rep. 2002; 6: 259-66.

6. Sarzi-Puttini P, Atzeni F, Mease PJ. Chronic widespread pain: from peripheral to central evolution. Best Pract Res Clin Rheumatol. 2011; 25: 133-9.

7. Stisi S, Cazzola M, Buskila D, Spath M, Giamberardino MA, Sarzi-Puttini P, et al. Italian Fibromyalgia Network. Etiopathogenetic mechanisms of fibromyalgia syndrome. Reumatismo. 2008; 60: 25-35.

8. Yunus MB. Fibromyalgia and overlapping disorders: the unifying concept of central sensitivity syndromes. Semin Arthritis Rheum. 2007; 36: 339-56.

9. Milligan ED, Watkins LR. Pathological and protective roles of glia in chronic pain. Nat Rev Neurosci. 2009; 10: 23-36.

10. Cassisi G, Sarzi-Puttini P, Alciati A, Casale R, Bazzichi L, Carignola R, et al. Italian Fibromyalgia Network. Symptoms and signs in fibromyalgia syndrome. Reumatismo. 2008; 60: 15-24.

11. Wolfe f, Smythe HA, Yunus MB, Bennett RM, Bombardier C, Goldenberg DL, et al. The American College of Rheumatology 1990 Criteria for the Classification of Fibromyalgia. Report of the Multicenter Criteria Committee. Arthritis Rheum. 1990; 33: 160-72.

12. Aaron LA, Buchwald D. A review of the evidence for overlap among unexplained clinical conditions. Ann Intern Med. 2001; 134: 868-81.

13. Jacobsen S, Danneskiold-Samsoe B, Lund B. Consensus document on fibromyalgia: the Copenhagen declaration. J Musculoske Pain. 1993; 1: 295-312.

14. Yunus MB, Masi AT, Aldag JC. Preliminary criteria for primary fibromyalgia syndrome (PFS): multivariate analysis of a consecutive series of PFS, other pain patients, and normal subjects. Clin Exp Rheumatol. 1989; 7: 63-9.

15. Wolfe F, Clauw DJ, Fitzcharles MA, Goldenberg DL, Katz RS, Mease P, et al. The American College of Rheumatology preliminary diagnostic criteria for fibromyalgia and measurement of symptom severity. Arthritis Care Res. 2010; 62: 600-10.

16. Jain KA, Carruthers M, Van De Sande MI, Barron R, Donaldson S, Dunne JV, et al. Fibromyalgia Syndrome: Canadian clinical working Case Definition, diagnostic and treatment protocols. A consensus document. J Musculoskelet Pain. 2003; 11: 3-107.

17. Reilly PA, Littlejohn GO. Peripheral arthralgic presentation of fibrositis/fibromyalgia syndrome. J Rheumatol. 1992; 19: 281-3.

18. Yunus MB, Masi AT, Aldag JC. A controlled study of primary fibromyalgia syndrome: clinical features and association with other functional syndromes. J Rheumatol. (Suppl.) 1989; 19: 62-71. 
19. Campbell SM, Clark S, Tindall EA, Forehand ME, Bennett RM. Clinical characteristics of fibrositis. I. A "blinded," controlled study of symptoms and tender points. Arthritis Rheum. 1983; 26: 817-24.

20. Pellegrino MJ. Atypical chest pain as an initial presentation of primary fibromyalgia. Arch Phys Med Rehabil. 1990; 71: 526-8.

21. Yunus MB, Aldag JC. Restless legs syndrome and leg cramps in fibromyalgia syndrome: a controlled study. BMJ. 1996; 312: 1336-9.

22. Cassisi G, Sarzi-Puttini P, Punzi L, Lazzarin P, Avossa M, Bedendo A, et al. Progetto Reumaveneto Group. Dolore e severità di malattia nell'ambulatorio di reumatologia rivolto al territorio; dati dal progetto reumaveneto. Reumatismo 2013; 65 (Spec 3): 419: 65

23. Granges G, Littlejohn GO. A comparative study of clinical signs in fibromyalgia/fibrositis syndrome, healthy and exercising subjects. J Rheumatol. 1993; 20: 344-51.

24. Holm LW, Carroll LJ, Cassidy JD, Skillgate E, Ahlbom A. Widespread pain following whiplash-associated disorders: incidence, course, and risk factors. J Rheumatol. 2007; 34: 193-200.

25. Macfarlane GJ. Generalized pain, fibromyalgia and regional pain: an epidemiological view. Best Pract Res Clin Rheumatol. 1999; 13: 403-14.

26. Bazzichi L, Rossi A, Massimetti G, Giannaccini G, Giuliano T, De Feo F, et al. Cytokine patterns in fibromyalgia and their correlation with clinical manifestations. Clin Exp Rheumatol. 2007; 25: 225-30.

27. Sarchielli P, Alberti A, Candeliere A, Floridi A, Capocchi G, Calabresi P. Glial cell linederived neurotrophic factor and somatostatin levels in cerebrospinal fluid of patients affected by migraine and fibromyalgia. Cephalalgia. 2005; 26: 409-15.

28. Gibson SJ, Littlejohn GO, Gorman MM, Helme RD, Granges G. Altered heat pain thresholds and cerebral event-related potentials following painful CO2 laser stimulation in subjects with fibromyalgia syndrome. Pain. 1994; 58: 185-93.

29. Geisser ME, Gracely RH, Giesecke T, Petzke FW, Williams DA, Clauw DJ. The association between experimental and clinical pain measures among persons with fibromyalgia and chronic fatigue syndrome. Eur J Pain. 2007; 11: 202-7.

30. Arroyo JF, Cohen ML. Abnormal responses to electrocutaneous stimulation in fibromyalgia. J Rheumatol. 1993; 20: 1925 31.

31. Cassisi GA, Todesco S, Ianniello A, Ceccherelli F, Giron GP. Pain in fibromyalgia syndrome: evaluation of pain threshold and psychological state. Scand J Rheum. 1992; 45: S161.

32. Gracely RH, Petzke F, Wolf JM, Clauw DJ. Functional magnetic resonance imaging evidence of augmented pain processing in fibromyalgia. Arthritis Rheum. 2002; 46: 1333-43.

33. Buskila D, Sarzi-Puttini P. Biology and therapy of fibromyalgia. Genetic aspects of fibromyalgia syndrome. Arthritis Res Ther. 2006; 8: 218.

34. Van Meurs JB, Uitterlinden AG, Stolk L, Kerkhof HJ, Hofman A, Pols HA, et al. A functional polymorphism in the catecholO-methyltransferase gene is associated with osteoarthritis-related pain. Arthritis Rheum. 2009; 60: 628-9.

35. Zubieta JK, Heitzeg MM, Smith YR, Bueller JA, Xu K, Xu Y, et al. COMT val158met genotype affects mu-opioid neurotransmitter responses to a pain stressor. Science. 2003; 299: 1240-3.

36. Grant MA, Farrell MJ, Kumar R, Clauw DJ, Gracely RH. fMRI evaluation of pain intensity coding in fibromyalgia patients and controls. Arthritis Rheum. 2001; 44: (Abstract).

37. Gracely RH, Geisser ME, Giesecke T, Nachemson A, Petzke F, Williams DA, et al. Pain catastrophizing and neural responses to pain among persons with fibromyalgia. Brain. 2004; 127: 835-43.

38. Gracely RH, Ambrose KR. Neuroimaging of fibromyalgia. Best Pract Res Clin Rheumatol. 2011; 25: 271-84.

39. Ceko M, Bushnell MC, Gracely RH. Neurobiology underlying fibromyalgia symptoms. Pain Res Treat. 2012; 2012: 585419.

40. Neugebauer V, Li W, Bird GC, Han JS. The amygdala and persistent pain. Neuroscientist. 2004; 10: 221-34.

41. Moldofsky H, Scarisbrick P, England R, Smythe H. Musculosketal symptoms and non-REM sleep disturbance in patients with "fibrositis syndrome" and healthy subjects. Psychosom Med. 1975; 37: 341-51.

42. Davies KA, Macfarlane GJ, Nicholl BI, Dickens C, Morriss R, Ray D, et al. Restorative sleep predicts the resolution of chronic widespread pain: results from the EPIFUND study. Rheumatology (Oxford). 2008; 47: 1809-13.

43. Buskila D, Cohen H. Comorbidity of fibromyalgia and psychiatric disorders. Curr Pain Headache Rep. 2007; 11: 333-8.

44. Raphael KG, Janal MN, Nayak S, Schwartz JE, Gallagher RM. Familial aggregation of depression in fibromyalgia: a communitybased test of alternate hypotheses. Pain. 2004; 110: 449-60.

45. Iannuccelli C, Sarzi-Puttini P, Atzeni F, Cazzola M, Di Franco M, Guzzo MP, et 
al. Psychometric properties of the Fibromyalgia Assessment Status (FAS) index: a national web-based study of fibromyalgia. Clin Exp Rheumatol. 2011; 29: S49-54.

46. Giesecke T, Gracely RH, Williams DA, Geisser ME, Petzke FW, Clauw DJ. The relationship between depression, clinical pain, and experimental pain in a chronic pain cohort. Arthtitis Rheum. 2005; 52: 1577-84.

47. Farrell MJ, VanMeter JW, Petzke F, Wolfe JM, Grant MAB, Clauw DJ, et al. Supraspinal activity associated with painful pressure in fibromyalgia is associated with beliefs about locus of pain control. Arthtitis Rheum. 2001; 44: S394 (Abstract).

48. Cummings M, Baldry P. Regional myofascial pain: diagnosis and management. Best Pract Res Clin Rheumatol. 2007; 21: 367-87.

49. Simons D. Update on myofascial pain from trigger points. PainEducation.com. Available from: http://www.pain-education.com/ myofascial-pain-from-trigger-points.html? Accessed: 01 Feb 2014.

50. Simons DG, Travell JG, Simons LS. Myofascial pain and disfunction: the trigger point manual, vol. 1. 2nd ed. Baltimore: Williams and Wilkins; 1999.

51. Harden RN, Bruehl SP, Gass S, Niemiec C, Barbick B. Signs and symptoms of the myofascial pain syndrome: a national survey of pain management providers. Clin J Pain. 2000; 16: 64-72

52. Giamberardino MA, Affaitati G, Fabrizio A, Costantini R. Myofascial pain syndromes and their evaluation. Best Pract Res Clin Rheumatol. 2011; 25: 185-98.

53. Gerwin RD. Myofascial pain syndromes from trigger points. Current Rev Pain. 1999; 3: 153-9.

54. Granges G, Littlejohn G. Prevalence of myofascial pain syndrome in fibromyalgia syndrome and regional pain syndrome: a comparative study. J Musculoskelet Pain. 1993; 1: 19-35.

55. Gerwin RD. A study of 96 subjects examined both for fibromyalgia and myofascial pain. J Musculoskelet Pain. 1995; 3: 121 (Abstract).

56. Mense S, Simons DG, Russell IJ. Muscle pain. Understanding its nature, diagnosis, and treatment. Philadelphia: Lippincott Williams \& Wilkins; 2001. p 385.

57. Hong C-Z, Chen Y-N, Twehous DA, Hong D. Pressure threshold for referred pain by compression on the trigger point and adjacent areas. J Musculoskelet Pain. 1996; 4: 61-79.

58. Gerwin RD, Dommerholt PT, Shah JP. An expansion of Simons' integrated hypothesis of trigger point formation. Curr Pain Headache Rep. 2004; 8: 468-75.
59. Couppe C, Midttun A, Hilden J, Jorgensen U, Oxholm P, Fuglsang-Frederiksen A. Spontaneous needle electromyographic activity in myofascial trigger points in the infraspinatus muscle: a blinded assessment. J Musculoskelet Pain. 2001; 9: 7-16.

60. Shah JP, Phillips TM, Danoff JV, Gerber LH. An in vivo microanalytical technique for measuring the local biochemical milieu of human skeletal muscle. J Appl Physiol. 2005; 99: 1977-84.

61. Affaitati G, Costantini R, Fabrizio A, Lapenna D, Tafuri E, Giamberardino MA. Effects of treatment of peripheral pain generators in fibromyalgia patients. Eur J Pain. 2011; 15: 61-9.

62. Srbely JZ. New trends in the treatment and management of myofascial pain syndrome. Curr Pain Headache Rep. 2010; 14: 346-52.

63. Srbely JZ, Dickey J, Lee D, Lowerison M. Needle stimulation of a myofascial trigger point causes segmental antinociceptive effects. J Rehab Med. 2010; 42: 463-8.

64. Giamberardino MA, Costantini R, Affaitati G, Fabrizio A, Lapenna D, Tafuri E, et al. Viscero-visceral hyperalgesia: characterization in different clinical models. Pain. 2010; 151: 307-22.

65. Mense S. Referral of muscle pain. J Am Phys Soc. 1994; 3: 1-9.

66. Rollman GB, Gillespie JM. The role of psyhosocial factors in temporomandibular disorders. Curr Rev Pain. 2000; 4: 71-81.

67. Martins RJ, Garbin CA, Garcia AR, Garbin AJ, Miguel N. Stress levels and quality of sleep in subjects with temporomandibular joint dysfunction. Rev Odonto Ciênc. 2010; 25: $32-6$

68. Guo C, Shi Z, Revington P. Arthrocentesis and lavage for treating temporomandibular joint disorders. Cochrane Database Syst Rev. 2009; (4): CD004973.

69. Dimitroulis G. Temporomandibular disorders: a clinical update. BMJ. 1998; 317: 190-4

70. Shi Z, Guo C, Awad M. Hyaluronate for temporomandibular joint disorders. Cochrane Database Syst Rev. 2003; (1): CD002970.

71. Barsky AJ, Borus JF. Functional somatic syndromes. Ann Intern Med 1999; 130: 910-21.

72. Manfredini D, Guarda-Nardini L, Winocur E, Piccotti F, Ahlberg J, Lobbezoo F. Research diagnostic criteria for temporomandibular disorders: a systematic review of axis I epidemiologic findings. Oral Surg Oral Med Oral Pathol Oral Radiol Endod. 2011; 112: 453-62.

73. Wassell R, Naru A, Steele J, Nohl F. Applied occlusion. London: Quintessence; 2008. pp 73-84. 
74. Guardia CF, Egan RA. Temporomandibular disorders. Medscape. Available from: http:// emedicine.medscape.com/article/1143410overview Accessed: 01 Jan 2014.

75. Mujakperuo HR, Watson M, Morrison R, Macfarlane TV. Pharmacological interventions for pain in patients with temporomandibular disorders. Cochrane Database Syst Rev. 2010; (10): CD004715.

76. Neville BW, Damm DD, Allen CA, Bouquot JE. Oral and maxillofacial pathology, 2nd ed. Philadelphia: WB Saunders; 2002; 758-9.

77. Cairns BE. Pathophysiology of TMD pain-basic mechanisms and their implications for pharmacotherapy. J Oral Rehabil. 2010; 37: 391-410.

78. Cawson RA, Odell EW, Porter S. Cawsons' essentials of oral pathology and oral medicine, 7th ed. Edinburgh: Churchill Livingstone; 2002.

79. IASP. Classification of chronic pain, part II, B. Relatively localized syndromes of the head and neck; group III: craniofacial pain of musculoskeletal origin. http://www. iasp-pain.org/files/Content/ContentFolders/ Publications2/ClassificationofChronicPain/ Part_II-B.pdf Retrieved 05/01/14.

80. Bhat S. Etiology of temporomandibular disorders: The journey so far. Int Dent SA. 2010; 12: 88-96.

81. Aggarwal VR, Lovell K, Peters S, Javidi H, Joughin A, Goldthorpe J. Psychosocial interventions for the management of chronic orofacial pain. In Aggarwal, Vishal R. Cochrane Database Syst Rev. 2011; (11): CD008456.

82. Orlando B, Manfredini D, Salvetti G, Bosco M. Evaluation of the effectiveness of biobehavioral therapy in the treatment of temporomandibular disorders: a literature review. Behav Med. 2007; 33: 101-18.

83. Kassler GD, Greene CS. The changing field of temporomandibular disorders: what dentists need to know. J Can Dent Assoc. 2009; 75: 49-53.

84. Kindler LL, Bennett RM, Jones KD. Central sensitivity syndromes: mounting pathophysiologic evidence to link fibromyalgia with other common chronic pain disorders. Pain Manag Nurs. 2011; 12: 15-24.

85. Beighton P, De Paepe A, Steinmann B, Tsipouras P, Wenstrup RJ. Ehlers-Danlos syndromes: revised nosology, Villefranche, 1997. Am J Med Genet. 1998; 77: 31-7.

86. Biro F, Gewanter HL, Baum J. The hypermobility syndrome. Pediatrics. 1983; 72: 701-6.

87. Hudson N, Fitzcharles MA, Cohen M, Starr MR, Esdaile JM. The association of softtissue rheumatism and hypermobility. $\mathrm{Br} \mathrm{J}$ Rheumatol. 1998; 37: 382-6.
88. Longley KE. Are joint hypermobility and fibromialgia connected? FMA UK 2003. Available from: http://www.fmauk.org/ dmdocuments/Joint\%20Hypermobility $\% 20$ \&\%20Fibromyalgia.pdf Accessed: 01 Feb 2014.

89. Karaaslan Y, Haznedaroglu S, Oztürk M. Joint hypermobility and primary fibromyalgia: a clinical enigma. J Rheumatol. 2000; 27: 1774-6.

90. Acasuso-Díaz M, Collantes-Estévez E. Joint hypermobility in patients with fibromyalgia syndrome. Arthritis Care Res. 1998; 11: 39-42.

91. Gedalia A, Press J, Klein M, Buskila D. Joint hypermobility and fibromyalgia in schoolchildren. Ann Rheum Dis. 1993; 52: 494-6.

92. Fitzcharles MA. Is hypermobility a factor in fibromyalgia? J Rheumatol. 2000; 27: 1587-9.

93. Ofluoglu D, Gunduz OH, Kul-Panza E, Guven $Z$. Hypermobility in women with fibromyalgia syndrome. Clin Rheumatol. 2006; 25: 291-3.

94. Sendur OF, Gurer G, Bozbas GT. The frequency of hypermobility and its relationship with clinical findings of fibromyalgia patients. Clin Rheumatol. 2007; 26: 485-7.

95. Holman AJ. Is hypermobility a factor in fibromyalgia? J Rheumatol. 2002; 29: 396-8.

96. Bulbena A, Duró JC, Porta M, Martín-Santos R, Mateo A, Molina L, et al. Anxiety disorders in the joint hypermobility syndrome. Psychiatry Res. 1993; 46: 59-68.

97. Martín-Santos R, Bulbena A, Porta M, Gago J, Molina L, Duró JC. Association between joint hypermobility syndrome and panic disorder. Am J Psychiatry. 1998; 155: 1578-83.

98. Rombaut L, Malfait F, De Paepe A, Rimbaut $\mathrm{S}$, Verbruggen $\mathrm{G}$, De Wandele I, et al. Impairment and impact of pain in female patients with Ehlers-Danlos syndrome: a comparative study with fibromyalgia and rheumatoid arthritis. Arthritis Rheum. 2011; 63: 1979-87.

99. Carville SF, Arendt-Nielsen S, Bliddal H, Blotman F, Branco JC, Buskila D, et al. EULAR evidence-based recommendations for the management of fibromyalgia syndrome. Ann Rheum Dis. 2008; 67: 536-41.

100. Burckhardt CS, Goldenberg D, Crofford L, Gerwin R, Gowans S, Kackson K, et al. Guideline for the management of fibromyalgia syndrome pain in adults and children. APS Clinical Practice Guideline Series, No. 4. Glenview, IL: American Pain Society; 2005.

101. Häuser W, Arnold B, Eich W, Felde E, Flügge $\mathrm{C}$, Henningsen $\mathrm{P}$, et al. Management of fibromyalgia syndrome - an interdisciplin- 
ary evidence-based guideline. Ger Med Sci. 2008; 6: Doc14.

102. Sarzi-Puttini P, Atzeni F, Salaffi F, Cazzola M, Benucci M, Mease PJ. Multidisciplinary approach to fibromyalgia: what is the teaching? Best Pract Res Clin Rheumatol. 2011; 25: 311-9.

103. Casale R, Cazzola M, Arioli G, Gracely RH, Ceccherelli F, Atzeni F, et al. Italian Fibromyalgia Network. Non pharmacological treatments in fibromyalgia. Reumatismo. 2008; 60: 59-69.

104. Bergman S. Management of musculoskeletal pain. Best Pract Res Clin Rheumatol. 2007; 21: 153-66.

105. Sarzi-Puttini P, Torta R, Marinangeli F, Biasi G, Spath M, Buskila D, et al. Italian Fibromyalgia Network. Fibromyalgia syndrome: the pharmacological treatment options. Reumatismo. 2008; 60: 50-8.

106. Cassisi G. Le sindromi dolorose miofas- ciali. In: Sarzi-Puttini P, Cazzola M, eds. Il manuale del paziente affetto da sindrome fibromialgica. Milano: GPAnet; 2009; 87103.

107. Levy HP. Ehlers-Danlos Syndrome, Hypermobility Type. In: Pagon RA, Adam MP, Bird TD, Dolan CR, Fong CT, Stephens K, eds. GeneReviews ${ }^{\mathrm{TM}}$. Seattle: University of Washington, Seattle; 1993-2013.

108. Bouloux GF. Use of opioids in long-term management of temporomandibular joint dysfunction. J Oral Maxillofac Surg. 2011; 69: 1885-91.

109. Greenberg MS, Glick M. Burket's oral medicine diagnosis and treatment. 10th ed. Hamilton, Ont.: BC Decker; 2003.

110. Cassisi G, Ceccherelli F, Atzeni F, SarziPuttini P. Complementary and alternative medicine in fibromyalgia: a practical clinical debate of agreements and contrasts. Clin Exp Rheumatol. 2013; 31: S134-52. 